\title{
Fuel Stream Modeling in Flowing Section of Sprayers of Diesel Nozzles
}

\author{
V.A. Markov \\ Head of Department «Piston Engines» \\ Bauman Moscow State Technical University \\ Moscow, Russia \\ vladimir.markov58@yandex.ru
}

\author{
V.G. Kamaltdinov \\ Professor of Department «Internal Combustion \\ Engines and Electronic Systems of Cars» \\ South Ural State University \\ Chelyabinsk, Russia \\ vkamaltdinov@yandex.ru
}

\author{
E.A. Savastenko \\ Post-graduate of Department «Heat Engineering and Heat Engines» \\ Russian University of Peoples' Friendship \\ Moscow, Russia \\ dozentrudn@mail.ru
}

\begin{abstract}
Achievement of required indexes of diesels is impossible without processes improvement of fuel spraying and mixture formation. Modern diesel fuel equipment does not provide a demanded number of the above-mentioned processes fully. Quality improvement of the processes is a goal of the study. Constructions of nozzles sprayers are offered. They increase turbulence of the fuel stream in epy flowing section of the sprayers. Fuel flow modeling is conducted in the flowing section of the sprayers. The experimental researches of the D-245.12Stype diesel equipped with developed sprayers are carried out. An opportunity of improvement of emissions toxicity indexes of the diesel with the sprayers mentioned above is shown.
\end{abstract}

Keywords-diesel engine; petroleum diesel fuel; nozzle; sprayer; needle; fuel flow; turbulization

\section{NECESSITY OF PERFECTING THE FUEL SPRAYING PROCESSES AND MIXTURE FORMATION IN DIESELS}

Processes quality of the fuel spraying and mixture formation predetermines substantially performance and effective indexes of transport diesels and indexes of exhaust gases toxicity. A design of the fuel supply system exerts a great influence on the nature of these processes. The most important element of the construction is nozzle forming injection characteristics and fuel spraying [1, 2]. Geometry characteristics of fuel jets, fuel jets structure, fuel spraying fineness and a row of parameters of the other fuel supply process depend on the nozzle design (sprayer firstly). Therefore numerous studies are undertaken. They are aimed at improving the design parameters of diesel spray nozzles for various purposes [3-9]. It was noted in these works that in order to improve the quality of the fuel atomization and mixture formation processes, it is expedient to provide additional turbulence of the fuel flow in the flow part of the atomizer nozzles by performing local hydraulic resistances in its elements. High turbulence of the fuel flow at the outlet from the spray holes leads to turbulization of the sprayed fuel jet, its rapid decay in the diesel engine combustion chamber, and improvement in the spraying and mixture formation rates. Various ways of performing such turbulators are proposed: making intersecting nozzle openings, producing spray channels with different turbulators, and making the spraying openings of local hydraulic resistances in the inlet and outlet sections. But the most simple and effective way to turbulize the fuel flow is the implementation of such turbulators on the nozzle needle. The research aim is a developing of nozzle atomizers that increase the fuel flow turbulence in the flowing part of the sprayers, modeling the fuel flow in the flowing part of these nebulizers and conducting experimental studies of the diesel with the developed sprayers.

\section{NOZZLES SPRAYERS' DEVELOPMENT WITH VARIABLE FLOW SECTION GEOMETRY}

Several experimental sprayers were developed and manufactured on the basis of the serial sprayer type-145 manufactured by the Noginsk Fuel Equipment Plant to assess the effect of hydraulic resistances made on the injector needle. The sprayers are used in FDM-22 nozzles of D-245.12S-type diesel (4 ChN 11/12.5) by Minsk Motor Factory. The serial sprayer is made with five spraying holes, the input edges of which are located in the nozzle well with a diameter of 1.2 $\mathrm{mm}$ (see Fig. 1). The holes spray diameter is $0.32 \mathrm{~mm}$, their length is $0.90 \mathrm{~mm}$, and the total effective area of the atomizer assembly is $0.278 \mathrm{~mm}^{2}$.

In the serial sprayer (Fig. 1, a) with a needle diameter of $5.0 \mathrm{~mm}$ (along the guide part), its maximum stroke was 0.26 $\mathrm{mm}$. The needle of the atomizer has three conical sections with different angles of these cones, equal to 45,60 and $90^{\circ}$. The needle is placed on the saddle of the sprayer with a diameter of $2.8 \mathrm{~mm}$ located on a section with a cone angle of $60^{\circ}$ (in Figure 1 this diameter is indicated by an asterisk "*"). 


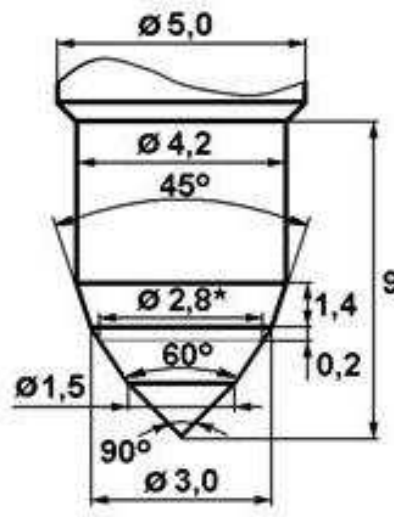

$a$

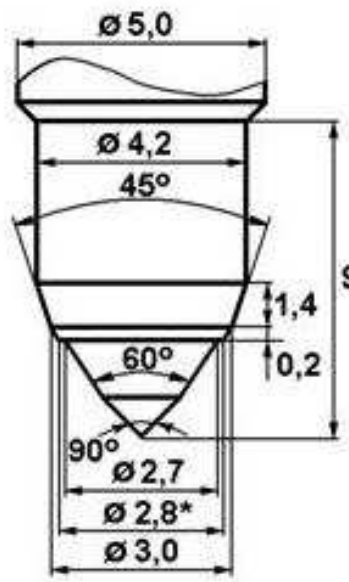

$c$



b

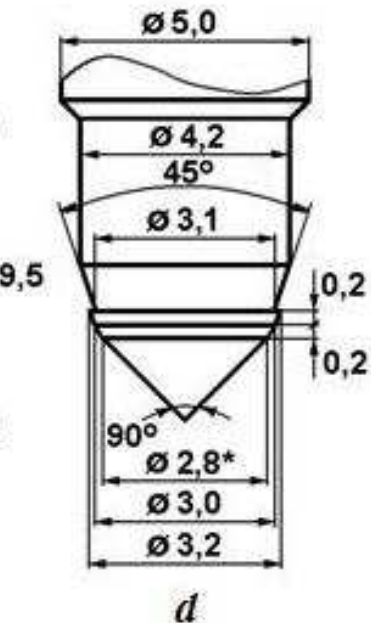

$d$
Fig. 1. Constructive diagrams of the sprayer needle tip: $a$ - serial sprayer; $b$ pilot sprayer No. $1 ; c$ - experimental sprayer № $2 ; d$ - pilot sprayer No. 3

In experimental sprayer No. 1 (Fig. 1, b), a part of the serial sprayer needle located below the landing diameter of $2.8 \mathrm{~mm}$ was cut at a cone angle of $90^{\circ}$. This trim of the nozzle tip causes the fuel, flowing through the throttling section, to expand further more intensively than in the standard spraybody, where the shank has a cone with a cone angle of $60^{\circ}$ below landing diameter $d_{p}=2.8 \mathrm{~mm}$. In experimental sprayer No. 2 (Figure 1,c), the conical needle part of the atomizer with a cone angle of $60^{\circ}$ is worn by $0.1 \mathrm{~mm}$ (diameter) lower the $2.8 \mathrm{~mm}$ diameter, fitting the diameter with the same cone angle $\left(60^{\circ}\right)$. As a result of this additional treatment, a horizontal annular shoulder is formed on the needle, having external and internal diameters of 2.8 and $2.7 \mathrm{~mm}$. Experimental sprayer No. 3 (Fig. 1, $d$ ) was obtained as a result of additional processing of experimental sprayer No. 1 (Fig. 1, $b)$. This after-treatment consisted in the fact that the conical part of the needle with a cone angle of $45^{\circ}$ was spaced $0.1 \mathrm{~mm}$ (in diameter) above the diameter of $3.2 \mathrm{~mm}$ with the same cone angle $\left(45^{\circ}\right)$. As a result of this after-treatment, a horizontal annular shoulder is formed on the needle, having outer and inner diameters of 3.2 and $3.1 \mathrm{~mm}$.

\section{FUEL STREAM MODELING IN THE FLOW SECTION OF THE NOZZLES SPRAYERS}

Preliminary experimental studies of the described atomizers showed that the best spraying quality of the fuel was provided by experimental sprayer No. 3 (Fig. 1, $d$ ). It is necessary to determine the dependence of the output flow parameters from the nozzle aperture on the flow section geometry to assess the geometry effect of the flow part nozzle sprayer on the formation of sprayed fuel jets. For this purpose, the calculated fuel flow in the exact part of the serial sprayer and pilot sprayer No. 3 was performed using the software complex Ansys CFX. After constructing a three-dimensional model of fuel volume, a final element grid is constructed on its basis. The grid was optimized to minimize the calculation time without compromising the result accuracy. The size of the grid was close to 2 million elements. The minimum size of the element is $1 \times 10^{-5} \mathrm{~m}$, which allowed fitting more than 25 layers of elements in the minimum geometric sections to ensure the required calculation quality.

Calculation preparation of fuel stream is carried out in the module CFX-Pre. In the flowing part of the atomizer there are zones in which fuel is sharply accelerated (for example, when rotating from the sub-head to the spraying hole) and a low pressure section with a turbulent eddy current is formed. This can lead to the formation of cavitation areas and the detachment of the fuel jet from the transition edge. In modeling such a flow, it is assumed that the fluid is incompressible and turbulent, and the flow process is adiabatic and isothermal. A scheme for setting the total pressure at the input of the system (in) and the static pressure at the outlet, (out) simulating the counter pressure, when fuel is injected into the combustion chamber (Fig. 2), was chosen as the boundary conditions.

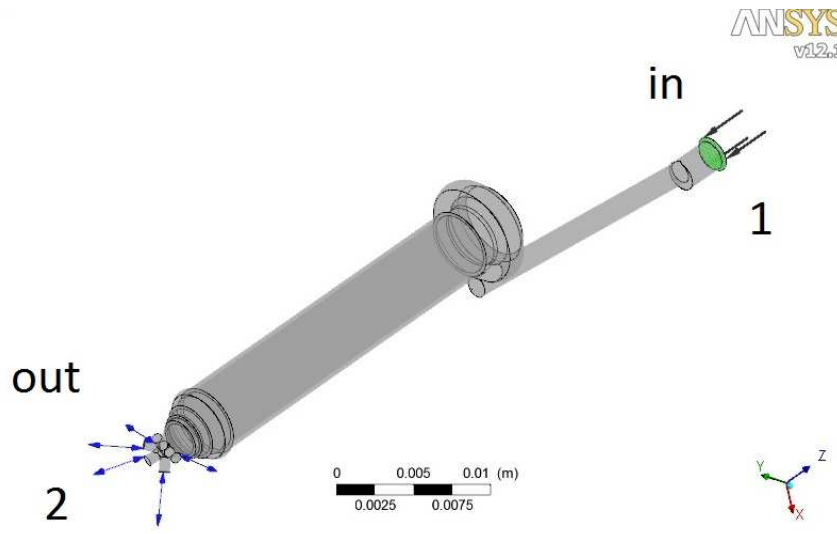

Fig. 2. The scheme for setting the boundary conditions when calculating the fuel consumption in the nozzle sprayer: 1 (in) - input section; 2 (out) - outlet cross-sections of spray holes

A preliminary calculation of the fuel flow at constant pressure at the inlet to the sprayer was made to the design model verification. This pressure is corresponded to the average injection pressure of fuel typical of the D-245.12S diesel fuel system at the nominal mode. The inlet pressure was assumed equal to $39.7 \mathrm{MPa}$ at the inlet, and at the output $0.1 \mathrm{MPa}$ (fuel injection into the atmosphere was simulated). At the same time, the fuel temperature was assumed equal to $40^{\circ}$ 
$\mathrm{C}$, and the effective cross section of the sprayer was 0.250 $\mathrm{mm}^{2}$. The fuel properties used in the calculation are listed in Table 1 .

TABLE I. THE FUEL PROPERTIES

\begin{tabular}{|c|c|}
\hline Properties & Values \\
\hline Density & $860 \mathrm{~kg} / \mathrm{m}^{3}$ \\
\hline Cinematic viscosity & $3.7 \mathrm{~mm} / \mathrm{c}$ \\
\hline Dynamic viscosity & $0,00446 \mathrm{~Pa} \cdot \mathrm{s}$ \\
\hline $\begin{array}{c}\text { The molecules molar mass in the } \\
\text { composition }\end{array}$ & $\begin{array}{c}110-230 \mathrm{~g} / \mathrm{mol}(\mathrm{in} \\
\text { counting } 170 \mathrm{~g} / \mathrm{mol})\end{array}$ \\
\hline Fuel heat capacity & $2100 \mathrm{~J} / \mathrm{kg} \cdot \mathrm{K})$ \\
\hline
\end{tabular}

The fuel consumption through the nozzle is determined as a result of the preliminary calculation. A simple model of turbulence was used for this calculation. The vortices intensity was set as initial conditions, both average at the inlet and high at the exit. A model was used that did not take into account the surface roughness and fuel adherence to the walls as the boundary conditions of the walls. As a result of the calculation, the fuel consumption is determined to be $79.2 \mathrm{~cm}^{3} / \mathrm{s}$, which corresponds to an effective cross section of the sprayer of $0.260 \mathrm{~mm}^{2}$. The difference in the actual and calculated values of the effective flow cross-section was $4 \%$, which allows using this model for comparative calculations and obtaining absolute values of the parameters.

The initial and boundary conditions in the comparative calculations are set to be the same. Only the needle shank geometry of the sprayer was different. All proposed variants of nebulizers were calculated, but for detailed comparative analysis, experimental sprayer No. 3 (Fig. 1,d) was chosen as the most effective. The distributions of the fuel flow rates in the flow parts of the indicated sprayers were obtained as a result of the comparative calculation researches of fuel flows in the serial atomizer and in the experimental nebulizer No.3 (Fig. 3). Analysis of the obtained current lines showed that they differ somewhat from each other, especially in the region of local resistance located on the needle of the experimental sprayer No.3. The maximum fuel flow rates are indicated in the spraying nozzles holes, where they exceed $200 \mathrm{~m} / \mathrm{s}$ for both variants of the sprayers.

The change in the distribution of the fuel flow rates in the flowing part of experimental sprayer No.3 in comparison with the serial sprayer is largely determined by the flow turbulization by local hydraulic resistances made in the region of the stop cone needle. This local hydraulic resistance is comparable to the hydraulic resistance of the spray holes located downstream of the fuel when the needle is in the fully raised position. The obtained distribution of the kinetic energy of turbulent vortices in the flow parts of the studied atomizers is shown in Fig.4. The region with increased turbulence of the fuel flow is displaced closer to the outlet edge of the spray hole in experimental sprayer No.3. The presence of local hydraulic resistance in the form of a stepped ledge, made on the needle of the sprayer, leads to the spreading of intense turbulent vortices almost to the entire length of the spraying hole in this atomizer (the region of these vortices is shown in Fig. 4 in red and green colors). In this case, the integral value of the kinetic energy of turbulence over the volume of the spraying hole of the experimental sprayer exceeds this value in the serial sprayer.
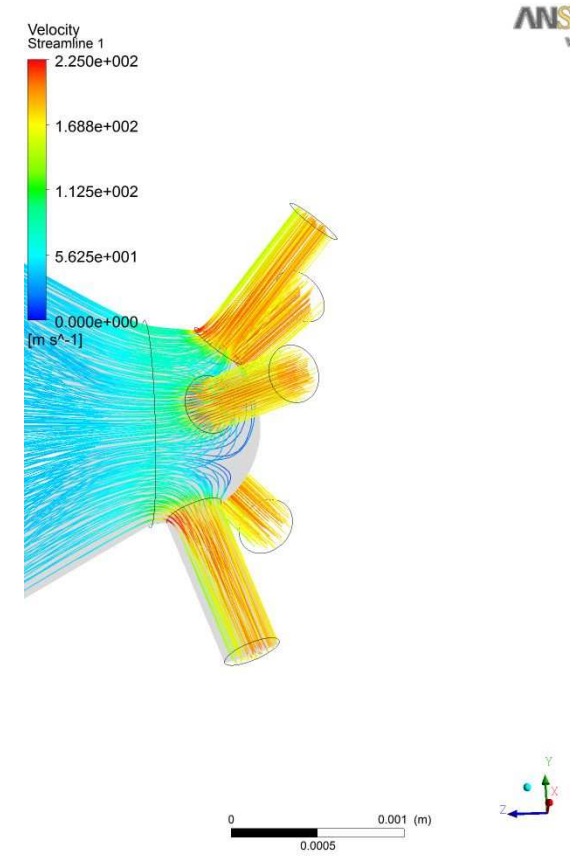

$\boldsymbol{A}$

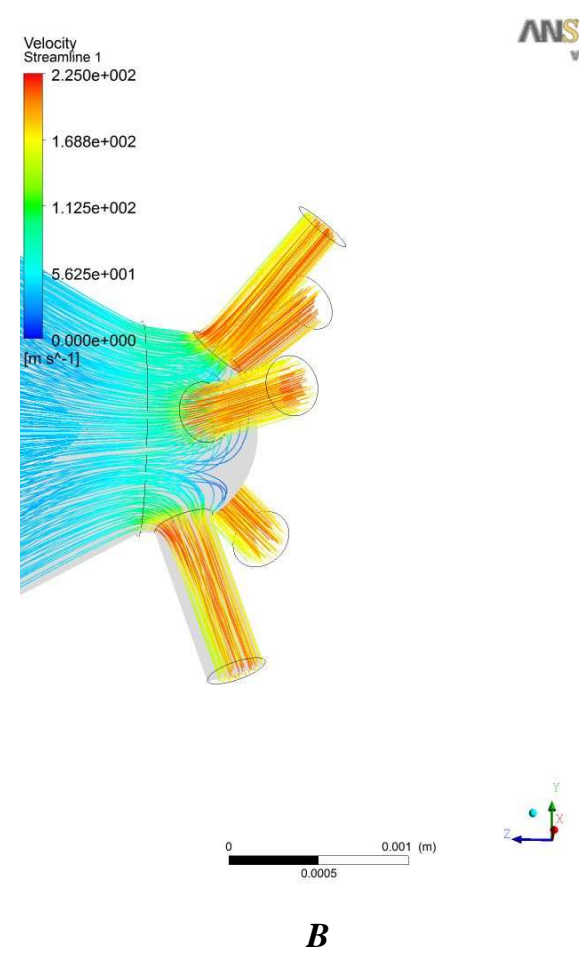

Fig.3. Fuel velocities distribution in the flowing sections of the nozzles sprayers: $A$ - serial sprayer; $B$ - experimental sprayer No.3 




$\boldsymbol{A}$

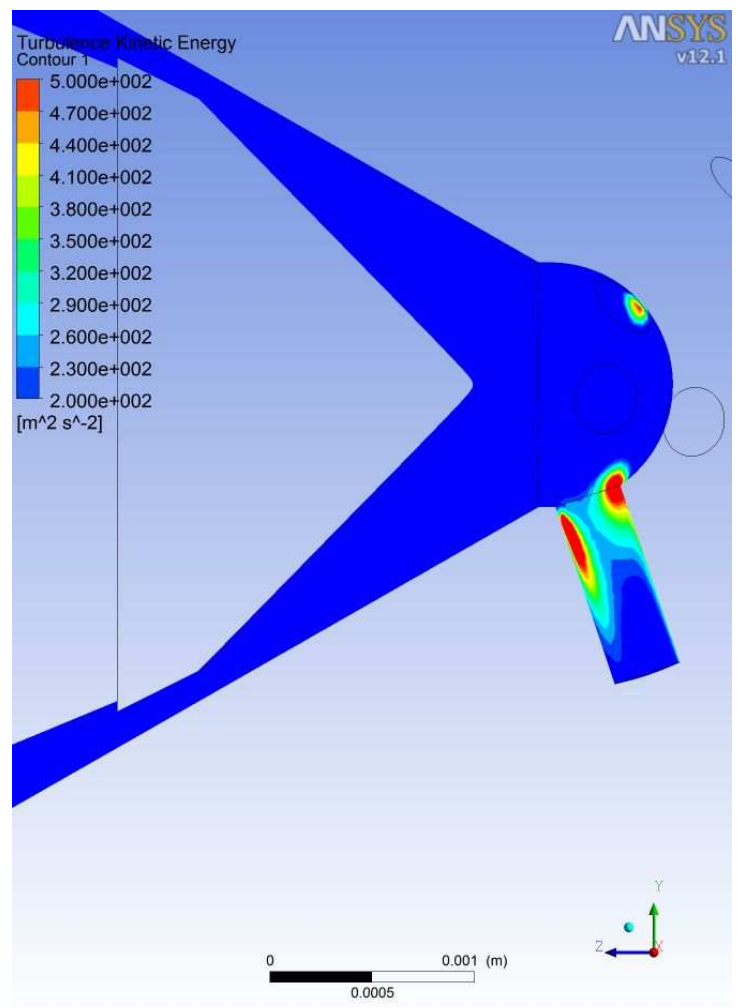

$B$

Fig.4. Kinetic energy distribution of the turbulent vortices in the spray holes of the nozzle sprayers: $A$ - serial sprayer; $B$ - experimental sprayer No. 3
The quality of the fuel atomization processes and mixture formation depends, first of all, on the fuel turbulence at the exit from the spraying holes of the spray guns. In this regard, a comparative evaluation of the flow parameters in this section was carried out for the serial and pilot sprayers. When processing the obtained distributions of the fuel flow parameters in the spray holes of these nozzles, some average values of the flow parameters were determined using the following relationships. The average velocity of fuel outflow was determined by the formula $[\mathrm{m} / \mathrm{s}]$ :

$$
\frac{\int_{S} \vec{U}}{S},
$$

where $S$ is the exit cross section area of the spray hole. The following expression is used to calculate the integral value of the energy of turbulent vortices [W]:

$$
\frac{\int_{s} \int_{\rho \vec{U}} k}{S}
$$

where $\rho \vec{U}$ is the mass fuel consumption for a given unit of area in which the value of the kinetic energy of turbulent vortices is $k$. The effective viscosity of the fuel $\mu_{e f f}$ was taken as the sum of $[\mathrm{Pa} \cdot \mathrm{s}]$ :

$$
\mu_{e f f}=\mu+\mu_{t}
$$

where $\mu_{t}$ is the turbulent viscosity, which is an additive to the physical viscosity of the liquid, at which the effective viscosity $\mu_{e f f}$ is equivalent to its value obtained from the momentum equation. The turbulent viscosity in the framework of $k-\varepsilon$ and $k-\omega$ models is related to the kinetic energy of turbulence by the following expression:

$$
\mu_{t}=C_{\mu} \rho \frac{k^{2}}{\varepsilon}
$$

where $C_{\mu}$ is a constant. The averaged values of the reduced turbulent viscosity were calculated from the formula $[\mathrm{Pa} \cdot \mathrm{c}]$ :

$$
\frac{\int_{s} \mu_{t}}{S}
$$

where $S$ is the exit cross section area of the spray hole. The mean values of the dissipation energy of turbulent vortices were determined using the expression $\left[\mathrm{m}^{2} / \mathrm{c}^{3}\right]$ :

$$
\frac{\int_{S} \varepsilon}{S}
$$

where $\varepsilon$ is the turbulent dissipation of the vortex. Some of the fuel flow rates, calculated from the presented formulas in the spray holes of the serial and pilot sprayers, are shown in Table 2 . 
TABLE II. SOME OF THE FUEL FLOW RATES

\begin{tabular}{|c|c|c|}
\hline Parameter & $\begin{array}{c}\text { Serial } \\
\text { sprayer }\end{array}$ & $\begin{array}{c}\text { Experimental } \\
\text { sprayer No3 }\end{array}$ \\
\hline Fuel expiration velocity $[\mathrm{m} / \mathrm{s}]$ & 172.829 & 172.886 \\
\hline Energy of turbulent vortices $[\mathrm{J} / \mathrm{kg}]$ & 150.727 & 146.699 \\
\hline Reduced turbulent viscosity $[\mathrm{Pa} \cdot \mathrm{s}]$ & 0.01892 & 0.02662 \\
\hline $\begin{array}{c}\text { Energy of turbulent vortices dispassion } \\
{\left[\mathrm{m}^{2} \mathrm{~s}^{3}\right]}\end{array}$ & 9.76 & 6.68 \\
\hline
\end{tabular}

Analysis of the Table 2 data showed that the parameters, characterizing the flow rate of the fuel and its consumption, vary relatively weakly with changes in the geometric dimensions of the part of the injector nozzle flow. But in this case, the parameters, characterizing the intensity of turbulent vortices vary over a fairly wide range. In particular, the average energy of the dissipation of turbulent vortices at the outlet from the spray hole is reduced by $31.54 \%$, when the transition from the standard to the experimental sprayer No.3 takes place.

\section{EXPERIMENTAL RESEARCHES OF THE DIESEL WITH DEVELOPED SPRAYERS}

Sets of the sprayers were manufactured and their motor tests were carried out on the D-245.12S diesel engine in accordance with the developed design diagrams of the nebulizers (Figure 1). This diesel has a semi-divided combustion chamber CRDI-type (Central Research Diesel Institute). The diesel was studied in the modes of the external speed characteristic and the 13-mode test cycle R49 with the same settings of the fuel supply system with the sprayers shown in Fig.1. Studies of the diesel engine at the external high-speed characteristic modes have shown that the use of sprayer No.3 has made it possible to reduce the specific effective fuel consumption and smoke of the exhaust gases in comparison with the serial atomizers (Table 3 ).

TABLE III. THE PARAMETERS OF THE DIESEL ENGINE AT THE EXTERNAL HIGH-SPEED CHARACTERISTIC MODES

\begin{tabular}{|c|c|c|}
\hline Parameter & $\begin{array}{c}\text { Serial } \\
\text { sprayer }\end{array}$ & $\begin{array}{c}\text { Experimental } \\
\text { sprayer №3 }\end{array}$ \\
\hline Fuel consumption per hour, $\mathrm{kg} / \mathrm{h}$ & $17.42 / 12.25$ & $19.60 / 12.50$ \\
\hline Diesel torque, $\mathrm{H} \cdot \mathrm{m}$ & $271 / 355$ & $320 / 363$ \\
\hline $\begin{array}{l}\text { Specific effective fuel } \\
\text { consumption, } \mathrm{g} /(\mathrm{\kappa} W \cdot \mathrm{h})\end{array}$ & $255.5 / 219.7$ & $243.4 / 219.1$ \\
\hline Effective diesel output & $0.332 / 0.386$ & $0.348 / 0.387$ \\
\hline $\begin{array}{c}\text { Exhaust smokiness, \% by } \\
\text { Hartridge scale }\end{array}$ & $16.0 / 28.0$ & $12.0 / 28.0$ \\
\hline
\end{tabular}

Note: the numerator indicates the parameter values for the maximum power mode at $\mathrm{n}=2400 \mathrm{rpm}$, in the denominator - on the maximum torque mode at $n=1500 \mathrm{rpm}$.

Tests of the D-245.12S diesel engine in the modes of 13mode test cycle R49 showed the possibility of improving the fuel economy and exhaust toxicity of diesel with experienced sprayers. According to the obtained content characteristics, the exhaust gases of the standard toxic components include: nitric oxides $\left(\mathrm{NO}_{\mathrm{x}}\right)$, carbon monoxide $(\mathrm{CO})$, unburned hydrocarbons
$\left(\mathrm{CH}_{\mathrm{x}}\right)$. Their integrated specific mass emissions were counted for the 13-mode cycle ( $e_{\mathrm{NOx}}, e_{\mathrm{CO}}, e_{\mathrm{CHx}}$ respectively) using the generally accepted methods. Conditional specific effective fuel consumption $g_{e}$ cond and conditional effective efficiency $\eta_{e}$ cond are used for the integral estimation of fuel efficiency in the regimes of this cycle. They are determined from the relationships:

$$
\begin{gathered}
g_{e \text { cond }}=\frac{\sum_{i=1}^{13} G_{\mathrm{т} i} \cdot K_{i}}{\sum_{i=1}^{13} N_{e i} \cdot K_{i}} \\
\eta_{e \text { cond }}=\frac{3600}{H_{U} \cdot g_{\text {econd }}},
\end{gathered}
$$

where $G_{\mathrm{Ti}}$ is the fuel consumption per hour in the $\mathrm{i}$-th mode; $\mathrm{H}_{\mathrm{U}}$ is the net calorific value of fuel $(\mathrm{MJ} / \mathrm{kg})$. The calculations results of the indicators are presented in Table 4 . The greatest effect on the improvement of the diesel performance was obtained using experimental sprayers No. 3 .

TABLE IV. THE EFFECT ON THE IMPROVEMENT OF THE DIESEL PERFORMANCE

\begin{tabular}{|c|c|c|}
\hline Parameter & $\begin{array}{c}\text { Serial } \\
\text { sprayer }\end{array}$ & $\begin{array}{c}\text { Experimental } \\
\text { sprayer } \text { №3 }\end{array}$ \\
\hline $\begin{array}{c}\text { Specific effective fuel } \\
\text { consumption, } g_{\text {e cond }}(\mathrm{g} / \mathrm{kW} \cdot \mathrm{h})\end{array}$ & 248.12 & 238.80 \\
\hline Effective output, $\eta_{\text {e ycл }}$ & 0.341 & 0.355 \\
\hline $\begin{array}{c}\text { Specific nitric oxides emissions, } \\
e_{\mathrm{NOx}}, \mathrm{g} /(\mathrm{kW} \cdot \mathrm{h})\end{array}$ & 6.610 & 7.125 \\
\hline $\begin{array}{c}\text { Specific carbon monoxide } \\
\text { emission, } e_{\mathrm{CO}}, \mathrm{g} /(\mathrm{kW} \cdot \mathrm{h})\end{array}$ & 3.612 & 2.602 \\
\hline $\begin{array}{c}\text { Specific hydrocarbons emission, } \\
e_{\mathrm{CHx}}, \mathrm{g} /(\mathrm{kW} \cdot \mathrm{h})\end{array}$ & 1.638 & 1.234 \\
\hline
\end{tabular}

\section{CONCLUSION}

The conducted researches confirmed the efficiency of the proposed designs of nozzles' atomizer and the possibility of improving the fuel economy and toxicity of diesel exhaust gases when equipped with experimental sprayers No. 3. The specific mass carbon monoxide emission $e_{\mathrm{CO}}$ decreased from 3.612 to $2.602 \mathrm{~g} /(\mathrm{kW} \cdot \mathrm{h})$ (i.e. by $28 \%$ ) when replacing serial sprayers with experimental sprayers No. 3 in the test diesel operating on 13-mode cycle. In addition, the specific mass hydrocarbon emission $e_{\mathrm{CHx}}$ reduced from 1.638 to 1.234 $\mathrm{g} /(\mathrm{kW} \cdot \mathrm{h})$ (i.e. by $24.7 \%$ ), the integral (conditional) specific effective fuel consumption $g_{e}$ cond lowered from 248.12 to $238.80 \mathrm{~g} /(\mathrm{kW} \cdot \mathrm{h})$ (i.e. by $3.8 \%)$, the integral effective output $\eta_{e}$ cond decreased from 0.341 to 0.355 . The smokiness of the exhaust gases reduced from 16 to $12 \%$ (i.e. by $25.0 \%$ ) by the Hartridge scale in the maximum power mode at $n=2400 \mathrm{rpm}$. And only the specific mass nitric oxides emissions $e_{\mathrm{NOx}}$ increased from 6.610 to $7.125 \mathrm{~g} /(\mathrm{kW} \cdot \mathrm{h})$ (i.e. by $7.8 \%$ ). But such increase in the emission of nitrogen oxides can be largely compensated by a decrease of fuel injection advance angle $\theta$. A decrease in $\theta$ by 1 degree of the crankshaft rotation leads to emission reduction of nitric oxides by $5-10 \%$ according to the 
data of the work [10]. But the emissions of other gaseous toxic components ( $\mathrm{CO}$ and $\mathrm{CHx})$ change insignificantly.

\section{References}

[1] V.A. Markov, S.N. Devyanin and V.I. Mal'chuk, "Fuel Injection and Spraying in Diesel Engines", Moscow, MGTU imeni N.E. Baumana Publ., 2007, 360 p.

[2] L.V. Grekhov, N.A. Ivaschenko and V.A. Markov, "Fuel Supply Systems and Diesel Engine Control Systems", Moscow, «LegionAvtodata» Publ, 2005, 344 p.

[3] C. Bae, J. Yu and J. Kang, "Effect on Nozzle Geometry on the Common-Rail Diesel Spray”, SAE Technical Paper Series, №2002-011625, pp. 1-13, 2002.

[4] L.C. Ganipa, S. Andersson and J. Chomiak, "Combustion Characteristics of Diesel Sprays from Equivalent Nozzles with Sharp and Rounded Inlet Geometries", Combustion Science Technologies, Vol. 175, pp. 1015-1032, 2003.

[5] K.H. Goney and M.L. Corradini, "Isolated Effects of Ambient Pressure, Nozzle Cavitation and Hole Inlet Geometry on Diesel Injector Spray
Characteristics”, SAE Technical Paper Series, № 2000-01-2043, pp. 114, 2000.

[6] J. Han, P. Lu and X. Xie, "Investigation of Diesel Spray Primary Breakup and Development for Different Nozzle Geometries", SAE Technical Paper Series, № 2002-01-2775, pp. 1-15, 2002.

[7] D. Hou, Y. Huang and M. Huo, "Spray and Atomization Characterization of a Micro-Variable Circular-Orifice (MVCO) Fuel Injector”, SAE Technical Paper Series, № 2011-01-0679, pp. 1-10, 2011.

[8] R. Payri, F.J. Salvador and J. Gimeno, "Effects of Nozzle Geometry on Direct Injection Diesel Engine Combustion Process", Applied Thermal Engineering, Vol. 29, pp. 2051-2060, 2009.

[9] A. Vanegas, H. Won and N. Peters, "Influence of the Nozzle Spray Angle on Pollutant Formation and Combustion Efficiency for a PCCI Diesel Engine”, SAE Technical Papers Series, № 2009-01-1445, pp. 1$12,2009$.

[10] V.A. Markov, R.M. Bashirov and I.I. Gabitov, "Toxicity of Diesel Engines Exhaust Gases", Moscow, MGTU imeni N.E. Baumana Publ., 2002,376 p. 